\title{
Burden And Coping Behaviour Among the Family Caregivers of the People With Mental Illness
}

\author{
Kafle B ${ }^{1}$, Bagale $\mathbf{Y}^{2}$ \\ 1. Assistant Professor, Dept Of Psychiatry, Devdaha Medical College, Rupandehi, Nepal 2. Nursing \\ Instructor, Devdaha Medical College, Rupandehi, Nepal \\ E-mail *Corresponding author : bikram12kafle@gmail.com
}

\begin{abstract}
Introduction: Caring for a person with mental disorder is a challenge for the caregivers. Little is known about the ways in which families cope while caring for a relative with mental illness in developing countries. This study has tried investigating the family burden and coping behaviour among the family caregivers of the people with mental illness.
\end{abstract}

Material And Method: This is a descriptive cross-sectional study conducted at Devdaha Medical College during the period of July 2019-December 2019. The research was approved by the Ethical Committee of the Institutional Review Board of Devdaha Medical College. The protocol approval number is 028/2019. Convenient sampling method was used. Data analysis was done in SPSS (Version 23, SPSS Inc, Chicago, USA). Results were presented as frequencies and percentages where required.

Results: Moderate Burden was experienced by $72 \%$ of the caregivers while the rest $28 \%$ experienced severe burden. People whose spouses were mentally ill had severe burden. Males coped with higher degree of problem and emotional focused coping strategy than females. Males felt more burden in comparison to the females and burden was found to be significantly higher among the caregivers who were taking care of their mentally ill spouses.

Conclusion: Caregiving is physically and psychologically demanding as it requires an enormous physical and emotional commitment as well as some basic skills. Teaching skills in the form of problem solving and communication are needed to promote the coping abilities and lessen the burden of caregivers.

Keywords: Caregivers; Developing countries; Mental disorder.

\section{INTRODUCTION}

The shift towards community care for patients with mental illness has resulted in transferring responsibility for day-to-day care of patients to their family members, which has led to profound psychosocial, physical and financial burdens on patients families. ${ }^{1}$ Families use a variety of coping strategies and resources to maintain healthy family functioning.

There is a dearth of information on burden among caregivers, and coping strategies used by caregivers for a relative with mental illness in developing countries. It is important to understand caregivers coping strategies for handling burden because it affects not only caregivers day to day functioning and is a constant source of stress, but how this stress is managed also has a bearing on the course of person's illness and prospects for improvement. ${ }^{2}$ The aim of the study was to explore family burden and coping behaviour among the family members of the people with mental illness.

\section{MATERIAL AND METHOD}

This is a descriptive cross-sectional study conducted at Devdaha Medical College and Research Institute during the period of July 2019 to December 2019. The research was approved by the Ethical Committee of the Institutional Review Board of Devdaha Medical College and Research Institute. The protocol approval number is $028 / 2019$. Using convenient sampling method 100 caregivers of psychiatric patients were selected. Caregivers above 18 years or more and staying with the patient currently and 
at least for last one year were included in the study.

The tools used for data collection were self designed semi structured proforma, Brief cope scale, Burden Assessment Schedule. Self designed semi structured proforma consist of socio-demographic characteristics of the study population which included age, sex, marital status ,educational status, occupation, socioeconomic status, relation with the patient, type of mental illness, total duration of illness and type of care provided.

Brief cope scale: The Brief cope is a self completed questionnaire measuring coping strategies developed by Carver CS. ${ }^{3}$ three composite subscales measuring emotionfocused, problem-focused and dysfunctional coping have proved useful in clinical research and have content validity. The scale can be administered to assess patient's coping strategies. The brief cope scale is of a 28 item self report measure of problem-focused versus emotion-focused coping skills. Caregivers are asked to respond to each item on a four-point Likert scale, indicating what they generally do and feel when they experience mental illness and related stressful events $((1=\mathrm{I}$ have not been doing this at all $-4=\mathrm{I}$ have been doing this a lot). The higher the score on each coping strategy, the greater the use of specific coping strategy. In the present study, based on the definitions of problem-focused coping, items 2,7,10,14,23, and 25 were classified as problem based coping and the rest of the items fell into emotion-based coping.

Burden Assessment Schedule (BAS): Burden Assessment Schedule was developed by Thara. ${ }^{4}$ The BAS was developed and standardized by step wise ethnographic exploration method. The inter rater reliability is high. It has high content validity. The values ranged between $0.71-0.82$. There are 40 items rated on a three point scale (1-3, 1- mild burden, 2- moderate burden \& 3- severe burden. A score up to 41-60 on BAS indicate mild burden, 61-80 indicate moderate burden, 81-100 indicate severe burden and 101-120 indicate very severe burden.

Data were analyzed using SPSS (Version 21, Chicago,Illinois, USA). Descriptive analysis was performed and mean, median and SD calculated. Data were explained in percentage. Pearson's correlation was used to determine the correlation between total duration of illness and burden in caregiver's with spouse mentally ill and without spouse mentally ill.

\section{RESULT}

There were $33(33 \%)$ caregivers within the age group $31-40,84(84 \%)$ of the caregivers were married. Fifty four $(54 \%)$ of the caregivers were from middle class family and $36(36 \%)$ caregivers were spouses while $64(64 \%)$ were other family members (Table 1 ).

Table 1: Socio-demographic characteristics of care giver of the mentally ill family members. $(\mathrm{N}=\mathbf{1 0 0 )}$

\begin{tabular}{|c|c|c|c|}
\hline \multicolumn{2}{|c|}{ Socio-demographic variables } & Frequency & Percentage \\
\hline \multirow[t]{2}{*}{ Sex } & Male & 50 & 50 \\
\hline & Female & 50 & 50 \\
\hline \multirow[t]{4}{*}{ Age group } & $<=20$ & 1 & 1 \\
\hline & $21-40$ & 61 & 61 \\
\hline & $41-60$ & 30 & 30 \\
\hline & $61+$ & 8 & 8 \\
\hline \multirow[t]{3}{*}{ Marital status } & Married & 84 & 84 \\
\hline & Single & 13 & 13 \\
\hline & $\begin{array}{l}\text { Separated+ } \\
\text { widow }\end{array}$ & 3 & 3 \\
\hline \multirow{6}{*}{$\begin{array}{l}\text { Educational } \\
\text { status }\end{array}$} & Illiterate & 8 & 8 \\
\hline & Literate & 16 & 16 \\
\hline & Primary & 15 & 15 \\
\hline & Secondary & 17 & 17 \\
\hline & Intermediate & 26 & 26 \\
\hline & Masters & 18 & 18 \\
\hline \multirow{4}{*}{$\begin{array}{l}\text { Socioeconomic } \\
\text { status }\end{array}$} & Upper & 4 & 4 \\
\hline & $\begin{array}{l}\text { Upper } \\
\text { middle }\end{array}$ & 38 & 38 \\
\hline & Middle & 54 & 54 \\
\hline & Lower & 4 & 4 \\
\hline \multirow{5}{*}{$\begin{array}{l}\text { Caregiver } \\
\text { relation with } \\
\text { patient }\end{array}$} & Parent & 34 & 34 \\
\hline & Spouse & 36 & 36 \\
\hline & Children & 13 & 13 \\
\hline & Sibling & 11 & 11 \\
\hline & Other & 6 & 6 \\
\hline
\end{tabular}

Table 2. Severity of Burden experienced by caregivers of mentally ill patients. $(\mathrm{N}=\mathbf{1 0 0})$

\begin{tabular}{|l|l|}
\hline Severity of Burden & $\%$ \\
\hline Mild & 0 \\
\hline Moderate & 72 \\
\hline Severe & 28 \\
\hline
\end{tabular}


It was found that $72(72 \%)$ experienced moderate burden and $28(28 \%)$ experienced severe burden (Table 2).The mean of problem-focused coping(PFC) strategy is obtained to be 17.83 with standard deviation 0.49 indicates that the care givers adopt more of PFC strategy than emotional focused strategy (taking mean 2.5 as cut-off point) (Table 3 ).

Table 3: Descriptive statistics of Problem Focused Coping (PFC), Emotion Focused Coping (EFC), and sex difference on burden, relationship of caregiver with mentally ill patient. $(\mathrm{N}=100)$

\begin{tabular}{|l|l|l|l|}
\hline $\begin{array}{l}\text { Types of } \\
\text { coping }\end{array}$ & $\begin{array}{l}\text { Mean } \\
\pm S D\end{array}$ & $\begin{array}{l}\text { Male } \\
(\text { Mean } \pm \text { SD) }\end{array}$ & $\begin{array}{l}\text { Female } \\
(\text { Mean } \pm S D)\end{array}$ \\
\hline PFC & $17.83 \pm 0.49$ & $3.06 \pm 0.46$ & $2.87 \pm 0.51$ \\
\hline EFC & $49.2 \pm 0.32$ & $2.27 \pm 0.35$ & $2.19 \pm 0.28$ \\
\hline $\begin{array}{l}\text { Caregiver's } \\
\text { relation } \\
\text { with } \\
\text { mentally ill }\end{array}$ & $82.44 \pm 7.53$ & $85.42 \pm 5.88$ & $79.11 \pm 7.92$ \\
\hline $\begin{array}{l}\text { Caregiver } \\
\text { with } \\
\text { spouse ill }\end{array}$ & $73.35 \pm 6.65$ & $74.20 \pm 6.83$ & $72.46 \pm 6.41$ \\
\hline $\begin{array}{l}\text { Caregiver } \\
\text { without } \\
\text { spouse ill }\end{array}$ & & & \\
\hline
\end{tabular}

The mean score of burden of the caregivers with spouse mentally ill was $82.44 \pm 7.53$ SD which indicates that the severe family burden whereas the mean score of the care givers with other family member ill was $73.35 \pm 6.65$ SD which indicates moderate burden. There is gender differences in feeling of family burden among caregivers with spouse mentally ill and caregivers with other family member ill (Table 3). From the mean results in both the cases, males feel more burden in comparison to the females. To examine the difference statistically significant, independent sample t-test is computed and was found to be statistically significant $(p=0.01)$ among the caregivers with spouse mentally ill (Table 4 ).

The total duration of illness is negatively associated with level of burden among caregivers when the spouses were mentally ill but has no association when the spouses were not mentally ill. However, in both the situations, the associations were not significant (Table 5).
Table 4: Independent sample t-test for sex differences of feeling family burden

\begin{tabular}{|c|c|c|c|c|c|c|c|}
\hline & \multicolumn{2}{|c|}{$\begin{array}{l}\text { Levene's } \\
\text { Test for } \\
\text { Equality } \\
\text { of } \\
\text { Variance } \\
\text { s }\end{array}$} & \multicolumn{4}{|c|}{ t-test for Equality of Means } \\
\hline & & $\mathrm{F}$ & $\begin{array}{l}\mathrm{Si} \\
\mathrm{g} .\end{array}$ & $\mathrm{T}$ & Df & Sig. & $\begin{array}{l}\text { Mean } \\
\text { differ } \\
\text { ence }\end{array}$ \\
\hline \multirow[b]{2}{*}{ RWSMI } & $\begin{array}{l}\text { Equal } \\
\text { variances } \\
\text { assumed }\end{array}$ & 1.61 & $\begin{array}{l}0 . \\
21\end{array}$ & 2.72 & 34 & 0.01 & 6.30 \\
\hline & $\begin{array}{l}\text { Equal } \\
\text { variances } \\
\text { not } \\
\text { assumed }\end{array}$ & & & 2.68 & 29.31 & 0.01 & 6.30 \\
\hline \multirow[b]{2}{*}{ RWOFMI } & $\begin{array}{l}\text { Equal } \\
\text { variances } \\
\text { assumed }\end{array}$ & 0.88 & $\begin{array}{l}0 . \\
34\end{array}$ & 1.28 & 94 & 0.20 & 1.73 \\
\hline & $\begin{array}{l}\text { Equal } \\
\text { variances } \\
\text { not } \\
\text { assumed }\end{array}$ & & & 1.28 & 93.95 & 0.20 & 1.73 \\
\hline
\end{tabular}

Table 5: Correlations between total duration of illness and burden score among caregivers with spouse ill and without spouse ill (p value).

\begin{tabular}{|l|l|}
\hline Burden score & $\begin{array}{l}\text { Total duration of } \\
\text { illness }\end{array}$ \\
\hline $\begin{array}{l}\text { Caregiver with spouse } \\
\text { mentally ill }\end{array}$ & $-0.264(0.12)$ \\
\hline $\begin{array}{l}\text { Caregiver without spouse } \\
\text { mentally ill }\end{array}$ & $0.002(0.986)$ \\
\hline
\end{tabular}

\section{DISCUSSION:}

The current study showed that $72 \%$ caregivers of mentally ill patients had experienced moderate amount of burden. The findings are consistent with the findings of Chakrabarti, who reported that $80 \%$ of the caregivers suffered from moderate amount of burden. 5 Similar findings were seen in the study by Howritz, and Oshodi. 6,7 The high percentage of burden experienced by caregiver could be because of more severe illness like schizophrenia and mood disorders present in our study, as our study site was also a tertiary centre where patient with 
more severe illness tend to report than neurotic disorders.

High mean score was seen in caregivers with spouse mentally ill than the caregivers with other family members ill. Males caregivers feel more burden than females caregivers when their spouses are mentally ill $(p<0.05)$. Similar findings were seen in a study conducted in Nigeria which showed males appeared to experience more than average burden than their female counterparts $(p<0.005) .{ }^{7}$ This might possibly be due to negative care giving appraisals coming from men who traditionally are not involved in care giving roles. Our result contradicts with the result of study conducted at UCMS Bhairahawa where female felt more burden compared to male ${ }^{8}$. Several studies have shown that female caregivers experience more distress than their male counterparts. ${ }^{9,10}$ Some studies showed that male and female caregivers feel same kind of burden and adopt similar type of coping styles. ${ }^{11,12}$

In our study it is seen that the total duration of illness is negatively associated with level of burden i.e. longer the duration of illness, feeling of burden gets reduced gradually. This might be because of the long average illness duration may have allowed the families in our study considerable time to adjust to the stresses and strains of caregiving and to learn coping skills. Another reason could be a significant number of patients may show improved functioning over time. In this regard there is evidence that persons who are provided with supports and skills in community living, appear over time to learn to live with the illness and recover from its effects. ${ }^{13}$

There were no statistical significant association between age, marital status, education, socioeconomic status and burden among caregiver of mentally ill patient. The findings are consistent with findings of study conducted in Egypt. ${ }^{9}$ The study conducted in China is not in agreement with the current study findings which showed that age of caregiver was positively correlated to burden of caregiver. ${ }^{14}$ When caregiver becomes older, they are worried about who will take care of their family member in future. Older caregiver also cannot provide care well to the patient. This study also showed that the education level has negative correlation with caregiver's burden. It is assumed that higher the level of education, higher the salary. High salary would decrease financial problem related to providing care for ill family member. Level of education of the caregiver also tends to have more knowledge to deal with the stressful event.

This study showed problem focused coping strategy was used more than emotion focused coping strategy and male used slightly more problem focused coping and emotional focused coping then female. The present study are in agreement with the study conducted at other parts of the globe which showed there is no difference between male and female caregivers coping startegies. ${ }^{15.16}$ Study conducted in India ${ }^{17}$ also showed problem solving as a better coping mechanism and can decrease the burden of illness on caregivers and may even improve the level of functioning of patients. ${ }^{17}$ This study contrasted with the findings by Hassan which showed the most coping strategies used by caregivers of schizophrenic patients was self controlling, positive reappraisal, and escape avoidance i.e. emotion focused coping was found more. 9 Similarly, Chandrasekaran reported that an emotion-focused coping strategy was found to be more commonly employed by the relatives, than other strategies. ${ }^{18}$ This could be because as the problem focused coping is considered the best type of coping strategy, it points out the ways of solving the problem and minimizes negative emotional consequences. ${ }^{11}$ In this approach an individual review the problems several times to enhance understanding, come up with a variety of probable solutions, work harder to manage the situation, analyze the problem bit by bit and seek assistance from others. One of the limitations of our study was small sample size and convenient sampling techniques, the results may not be generalizable to all relatives of people with mental illness.

\section{CONCLUSION:}

The presence of a person with mental disorder in a family is often associated with a significant objective and subjective burden on other family members. The large prevalence of more than average burden among almost half of the caregivers emphasizes the importance of investigating the impact of such burden. Caregiving is physically and psychologically 
demanding as it requires an enormous physical and emotional commitment as well as some basic skills. So teaching skills in the form of problem solving and communication are needed to promote the coping abilities and lessen the burden of caregivers.

\section{ACKNOWLEDGEMENT: None}

\section{FUNDING: None}

\section{CONFLICT OF INTEREST: None}

\section{REFERENCES:}

1. Sahoo S, Brahma PK, Mohapatra PK. Burden of caregiver's among the mentally ill and diabetic patients - a comparative study. Orissa Journal of psychiatry. 2010: 39-47.

2. Scazufca M, Kuipers E. Coping strategies in relatives of people with schizophrenia before and after psychiatric admission. The British journal of psychiatry. 1999 Feb; 174(2):154-8.

3. Carver CS. You want to measure coping but your protocol'too long: Consider the brief cope. International journal of behavioral medicine. 1997 Mar 1;4(1):92.

4. Thara $R$, Padmavati $R$, Kumar S, Srinivasan L. Instrument to assess burden on caregivers of chronic mentally ill. Indian Journal of Psychiatry. 1998 Jan;40(1):21.

5. Chakrabarti S, Kulhara P, Verma SK. Family Burden Of Neurosis: And Determinants. Hong Kong Journal of Psychiatry. 1996;6(1):23-8.

6. Howritz $A V$, Reinhand SC. Ethnic differences in caregiving duties and burdens among parents and siblings of persons with severe mental illness. J Health Soc Behav. 1995: 39: 138-50.

7. Oshodi YO, Adeyemi JD, Aina OF, Suleiman TF, Erinfolami AR, Umeh C. Burden and psychological effects: caregiver experiences in a psychiatric outpatient unit in Lagos, Nigeria. African journal of psychiatry. 2012;15(2):99-105.

8. Kamala Darlami, Reshmi Ponnose, Pradap Jose. Caregiver's stress of psychiatric patients. .Journal of Universal College of Medical Sciences (2015) Vol.03 No.02 Issue 10.

9. Hassan WA, Mohamed II, Elnaser AE, Sayed NE. Burden and coping strategies in caregivers of schizophrenic patients. Journal of American Science. 2011;7(5):802-11.

10. George MR, Raju S. Perceived Stress, Ways of Coping and Care Giving Burden among Family Caregivers of Patients with Schizophrenia. HINDU. 2006 May 25.

11. Fitzpatrick KE, Vacha-Haase T. Marital satisfaction and resilience in caregivers of spouses with dementia. Clinical gerontologist. 2010 May 28;33(3):165-80.

12. Sreeja I, Sandhya G, Rakesh I, Singh M. Comparison of burden between family caregivers of patients having schizophrenia and epilepsy. The Internet Journal of Epidemiology. 2009;6(2):1-2.

13. Harding CM, Brooks GW, Ashikaga T, Strauss JS, Breier A. The Vermont longitudinal study of persons with severe mental illness, II: Long-term outcome of subjects who retrospectively met DSM-III criteria for schizophrenia. American journal of Psychiatry. 1987 Jun 1;144(6):727-35.

14. Li J, Lambert CE, Lambert VA. Predictors of family caregivers' burden and quality of life when providing care for a family member with schizophrenia in the People's Republic of China. Nursing $\mathcal{E}$ health sciences. 2007 Sep;9(3):192-8.

15. DiBartolo MC, Soeken KL. Appraisal, coping, hardiness, and self-perceived health in community-dwelling spouse caregivers of persons with dementia. Research in Nursing \& Health. 2003 Dec; 26(6):445-58.

16. Adams B, Aranda MP, Kemp B, Takagi K. Ethnic and gender differences in distress among Anglo American, African American, Japanese American, and Mexican American spousal caregivers of persons with dementia. Journal of Clinical Geropsychology. 2002 Oct 1;8(4):279-301.

17. Creado DA, Parkar SR, Kamath RM. A comparison of the level of functioning in chronic schizophrenia with coping and burden in caregivers. Indian Journal of Psychiatry. 2006 Jan;48(1):27.

18. Chandrasekaran $R$, Sivaprakash B, Jayestri SR. Coping startegies of the relatives of schizophrenic patients. Indian Journal of Psychiatry. 2002 Jan;44(1):9. 